\title{
ANALISIS IMPLEMENTASI PEMBELAJARAN KIMIA DALAM PROGRAM FULL DAY SCHOOL
}

\author{
I Ketut Bandem Elyadi ${ }^{1}$, I Wayan Subagia ${ }^{2}$, Siti Maryam ${ }^{3}$ \\ 1,2,3 Universitas Pendidikan Ganesha \\ Singaraja, Indonesia \\ e-mail: ketut.bandem.elyadi@undiksha.ac.id ${ }^{1}$, wayan.subagia@undiksha.ac.id ${ }^{2}$, \\ siti.Maryam@undiksha.ac.id ${ }^{3}$
}

\begin{abstract}
Abstrak
Penelitian ini bertujuan untuk mendeskripsikan dan menjelaskan pendekatan, metode, model pembelajaran, sumber belajar yang digunakan, dan distribusi waktu belajar siswa dalam program full day school di SMA Negeri Bali Mandara. Subjek dalam penelitian ini adalah RPP, penjadwalan pembelajaran kimia, guru, dan siswa. Metode yang digunakan dalam pengumpulan data adalah observasi, studi dokumen, dan wawancara. Data disajikan dengan deskriptif kualitatif. Hasil penelitian ini adalah sebagai berikut. (1) Pendekatan pembelajaran yang digunakan dalam program full day school di SMA Negeri Bali Mandara, yaitu pendekatan saintifik. (2) Metode pembelajaran yang digunakan, yaitu tanya jawab, diskusi, presentasi, penugasan, dan praktikum. (3) Model pembelajaran yang digunakan, yaitu inkuiri terbimbing, discovery learning, dan problem based learning. (4) Sumber belajar yang digunakan, yaitu buku paket kimia, internet, video dan e-learning. (5) Waktu pembelajaran kimia dominan dialokasikan pada pagi hari. Implementasi pembelajaran kimia dalam program full day school belum berjalan sesuai dengan kurikulum 2013.
\end{abstract}

Kata kunci: Asam Basa, Think Pair Share, Penelitian dan Pengembangan

\begin{abstract}
This research aimed to describe and explain the the approaches, methods, learning models, learning resources used, and the distribution of student learning time in the full day school program at Bali Mandara High School. The subjects in this study were lesson plans, scheduling of learning chemistry, teachers, and students. The methods used in data collection are observation, document study, and interview. Data presented with descriptive qualitative. The results of this study are as follows. (1) The learning approach used in the full day school program at Bali Mandara State High School is a scientific approach. (2) Learning methods used, namely question and answer, discussion, presentation, assignment, and practicum. (3) The learning model used, namely guided inquiry, discovery learning, and problem based learning. (4) Learning resources used, namely chemistry textbooks, the internet, video and e-learning. (5) The dominant chemical learning time is allocated in the morning. The implementation of
\end{abstract}


chemistry learning in the full day school program has not run according to the 2013 curriculum.

Keywords: Acid Base, Think Pair Share, Research and Development

\section{PENDAHULUAN}

Kurikulum 2013 merupakan kurikulum yang diterapkan dalam kegiatan belajar mengajar yang mengintegrasikan dua kerangka besar yaitu kompetensi dan karakter dalam diri peserta didik (Sulaeman, 2015). Kurikulum 2013 diimplementasikan dalam bentuk program enam hari sekolah dan lima hari sekolah (full day school) dalam proses pembelajaran. Program pendidikan tersebut diterapkan dengan harapan siswa dapat mengasah kemampuan yang dimiliki dalam program pendidikan yang diterapkan. Program enam hari sekolah merupakan pembelajaran konvensional dalam waktu enam setengah jam sampai tujuh jam yang dilakukan dari pagi hari hingga siang hari. Program enam hari sekolah dalam proses pembelajaran digunakan sepenuhnya untuk belajar. Guru diperbolehkan untuk memberikan pekerjaan rumah (PR) kepada siswa dalam proses pembelajaran. Program full day school menerapkan pembelajaran atau kegiatan belajar mengajar dari pagi hingga sore hari dengan memadukan jam pelajaran untuk pendalaman materi pelajaran serta pengembangan diri dan kreatifitas (Islami, 2016). Program full day school dari pagi hingga sore hari mengakibatkan waktu, aktivitas maupun kesibukan siswa akan lebih banyak dihabiskan di lingkungan sekolah daripada di rumah. Selain itu, dalam pembelajaran siswa dibebaskan dengan pekerjaan rumah (PR).

Penerapan program full day school belum sepenuhnya dilakukan oleh seluruh sekolah. Hal tersebut terbukti dengan adanya sekolah yang sudah menerapkan program full day school dan ada yang belum menerapkan program full day school. Sekolah Negeri yang sudah menerapkan program full day scholl di kota Singaraja diantaranya SMA Negeri 1 Singaraja, SMA Negeri 3 Singaraja, dan SMA Negeri 4 Singaraja. Sekolah Negeri di kota Singaraja yang belum menerapkan program full day scholl yaitu SMA Negeri 2 Singaraja. Salah satu alasan sekolah belum menerapkan program full day school adalah kurangnya sarana, prasana yang memadai dan sumber daya manusia (SDM). Peningkatan sumber daya manusia (SDM) seperti tenaga kependidikan, staf ahli, laboran, dan juga administrasi merupakan fokus dalam rangka mendukung penerapan program full day school (Hidayah, 2017). Peningkatan mutu sarana dan prasarana pendidikan juga harus mendukung dalam penerapan full day school. Peningkatan sarana dan prasarana pendidikan untuk peralatan dan ruang laboratorium dapat menunjang pelaksanaan pembelajaran di sekolah (Hidayah, 2017).

Program enam hari sekolah dan program full day school memiliki persamaan dan perbedaan. Persamaan kedua program tersebut yaitu sama-sama diimplementasikan dalam kurikulum 2013 dengan mata pelajaran yang sama, jumlah waktu belajar yang sama, dan tujuan kompetensi yang sama. Perbedaan kedua program tersebut terletak pada waktu dan proses pembelajaran. Waktu program enam hari sekolah berlangsung selama enam hari sedangkan full day school berlangsung selama lima hari. Program enam hari sekolah dari pagi sampai sore hari selama enam setengah hingga tujuh jam sehari, sedangkan program full day school dari pagi sampai sore hari selama delapan jam sehari. Perbedaan lain dilihat dari proses pembelajaran. Guru diperbolehkan untuk memberikan pekerjaan rumah (PR) kepada siswa dalam program enam hari sekolah, sedangkan pada program full day school siswa dibebaskan dari pekerjaan rumah (PR). Perbedaan antara program enam hari sekolah dengan program full day school mengakibatkan perubahan pada pelaksanaan pembelajaran dari segi waktu dan proses pembelajaran. Berdasarkan perubahan tersebut, peneliti ingin melihat pelaksanaan pembelajaran kimia yang dikelola secara umum dengan pengurangan hari dalam program full day school di SMA Negeri Bali Mandara.

Berdasarkan perbedaan program enam hari sekolah dengan lima hari sekolah (full day school) perlu dikaji secara mendalam. Kajian mendalam penting dilakukan agar dapat mengetahui gambaran mengenai "Implementasi Pembelajaran Kimia dalam Program Full Day School di SMA Negeri Bali Mandara". Hasil penelitian ini diharapkan dapat memberikan gambaran mengenai pelaksanaan pembelajaran kimia dikelola secara umum dengan pengurangan hari yang terjadi dalam program full day school, sehingga dapat dijadikan sebagai bahan kajian dalam program pendidikan. 


\section{METODE}

Tabel 1. Hubungan antara Masalah, Sumber data, Instrumen, dan Teknik Pengumpulan Data

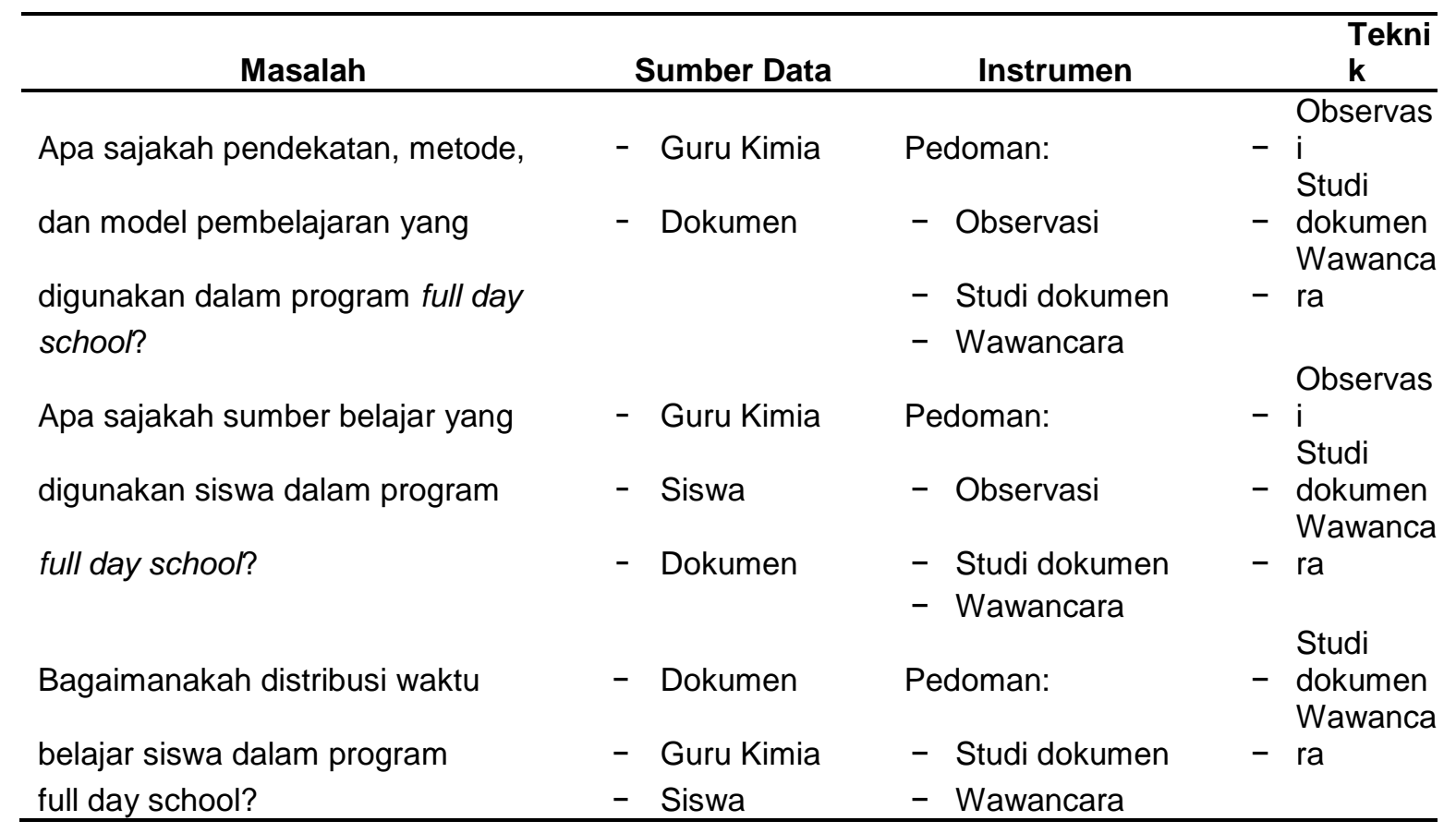

Data disajikan dengan deskriptif kualitatif dengan langkah, yaitu pengumpulan data, reduksi data, penyajian data, dan penarikan kesimpulan/verifikasi. Keabsahan data dilakukan dengan triangulasi teknik dan triangulasi sumber.

\section{HASIL DAN PEMBAHASAN}

1) Pendekatan Pembelajaran

Pendekatan pembelajaran yang digunakan dalam program full day school di SMA Negeri Bali Mandara adalah pendekatan saintifik. Pada pelaksanaannya, pembelajaran kelas X MIPA dimulai dari mengamati permasalahan yang terdapat dalam Unit Kegiatan Belajar Mandiri (UKBM). Kemudian siswa mengumpulkan informasi dari berbagai sumber. Siswa mengolah informasi yang diperoleh setelah mendapatkan informasi. Setelah itu, siswa mengkomunikasikan hasil temuan dari dikusi kelompok. Pada kelas XI MIPA, proses pembelajaran dimulai pada saat melakukan praktikum dan siswa mengamati proses yang terjadi. Setelah siswa melakukan praktikum, guru meminta siswa untuk menyampaikan hasil yang telah diperoleh dalam praktikum tersebut. Siswa mengkomunikasikan maksud praktikum yang telah dilakukan. Kelas XI MIPA melakukan pengerjaan Unit Kegiatan Belajar Mandiri (UKBM) dan berdiskusi dengan teman yang lain, mencari sendiri informasi di berbagai sumber, hingga bertanya ke guru pada pertemuan selanjutnya. Berdasarkan hal tersebut siswa yang lebih aktif dan tidak cenderung pasif dalam pembelajaran, sehingga dapat disimpulkan bahwa pendekatan yang digunakan yaitu pendekatan santifik. Pada RPP guru kelas X dan XI MIPA, pendekatan yang digunakan yaitu pendekatan saintifik. Pada pendekatan saintifik, pembelajaran berpusat pada siswa. Prinsip pendekatan saintifik menurut Nurdyansyah dan Fahyuni (2016) menyatakan bahwa siswa mencari tahu apa yang terjadi, menemukan jawabannya sendiri, dan membandingkan temuannya dengan temuan siswa lainnya.

Kelas XII MIPA pembelajaran yang dilakukan hanya pembahasan latihan soal. Pembahasan latihan soal dilakukan untuk mempersiapkan siswa menghadapi Ujian Nasional Berbasis Komputer (UNBK). Pada RPP, pendekatan yang digunakan yaitu pendekatan saintifik. Hal tersebut tidak sesuai dengan prinsip dari pembelajaran saintifik. Pembelajaran saintifik dirancang agar peserta didik secara aktif mengkonstruksi konsep, hukum dan prinsip melalui tahapan-tahapan mengamati (untuk mengidentifikasi masalah atau menemukan masalah), merumuskan masalah, mangajukan atau merumuskan hipotesis, mengumpulkan data dengan berbagai teknik, menganalisis data, menarik kesimpulan dan mengkomunikasikan (Hosnan dalam Nurdyansyah dan Fahyuni, 2016). 


\section{2) Metode Pembelajaran}

Metode pembelajaran yang digunakan guru pada kelas X, XI dan XII MIPA yaitu tanya jawab, diskusi, penugasan, praktikum, dan presentasi. Metode tanya jawab, diskusi dan presentasi dilakukan oleh guru kimia kelas X MIPA pada setiap pertemuan. Metode tanya jawab dan praktikum juga dilakukan oleh guru kimia kelas XI MIPA pada setiap pertemuan. Metode tanya jawab dan diskusi dilakukan oleh guru kimia kelas XII MIPA pada setiap pertemuan. Metode tanya jawab digunakan oleh guru saat memberikan penjelasan materi pelajaran. Guru juga menggunakan metode tanya jawab saat memberikan tanggapan mengenai jawaban atau presentasi siswa. Metode presentasi dilakukan saat siswa menjelaskan jawaban yang telah didiskusikan dalam kelompoknya. Metode penugasan digunakan oleh guru setelah suatu materi selesai diajarkan. Tugas yang harus dikumpulkan siswa adalah UKBM, karena syarat mengikuti ulangan harian adalah mengumpulkan jawaban dari UKBM mengenai materi ulangan harian. Siswa melanjutkan mengerjakan tugas UKBM di asrama jika belum selesai mengerjakan dalam diskusi kelompok.

Dalam program full day school, siswa dibebaskan dengan Pekerjaan Rumah (PR). Namun, siswa melanjutkan mengerjakan UKBM di asrama jika belum selesai mengerjakan dalam diskusi kelompok. Hal tersebut tentunya tidak sesuai dengan proses pembelajaran full day school. Proses pembelajaran full day school tidak memperbolehkan siswa mendapatkan PR. Berdasarkan Permendikbud RI Nomor 23 Tahun 2017 yang menyatakan bahwa hari sekolah digunakan bagi peserta didik untuk melaksanakan kegiatan intrakurikuler, kokurikuler, dan ekstrakurikuler. Oleh karena itu, pembelajaran harus tuntas di sekolah. Artinya, tidak ada lagi pekerjaan rumah (PR) yang dibebankan kepada siswa.

Metode yang digunakan guru belum sepenuhnya sesuai dengan perencanaan yang telah dirancang. Metode yang digunakan guru kelas X, XI, dan XII MIPA berbeda dengan metode yang dicantumkan pada RPP. Berdasarkan hasil studi dokumen metode yang digunakan dalam pembelajaran kimia di kelas X MIPA adalah metode praktikum, diskusi tanya jawab, penugasan dan presentasi. Namun, kegiatan pembelajaran yang dilakukan oleh guru dominan menggunakan metode tanya jawab, diskusi dan presentasi. Metode praktikum yang direncanakan tidak dilakukan oleh guru. Hal tersebut karena alat parktikum tidak bisa digunakan. Berdasarkan hasil studi dokumen, metode yang digunakan dalam pembelajaran kimia di kelas XI MIPA adalah metode praktikum, diskusi, tanya jawab, penugasan dan presentasi. Namun, guru dominan menggunakan metode tanya jawab dan diskusi. Pertemuan selanjutnya, siswa hanya pengerjaan Unit Kegiatan Belajar Mandiri (UKBM). Berdasarkan hasil studi dokumen, metode yang digunakan dalam pembelajaran kimia di kelas XII MIPA adalah metode diskusi, eksperimen, latihan, dan penugasan. Namun, materi pelajaran kelas XII MIPA sudah selesai dipelajari. Oleh karena itu, metode yang dominan terlihat adalah metode tanya jawab dan diskusi.

\section{3) Model Pembelajaran}

Model pembelajaran yang digunakan guru dalam program full day school adalah inkuiri terbimbing, discovery learning, dan problem based learning. Model pembelajaran yang digunakan sudah sesuai dengan tuntutan kurikulum 2013, namun model pembelajaran yang digunakan belum sesuai dengan perencanaan yang telah dirancang. Model pembelajaran yang direkomendasikan sesuai kurikulum 2013, yaitu discovery learning, problem based learning, inquiry learning, dan project based learning (Permendikbud RI, 2016). Pelaksanaan pembelajaran di kelas X MIPA, guru memberikan rangsangan pengetahuan kepada siswa, kemudian guru menguatkan pengetahuan siswa dengan menjelaskan materi. Siswa mengidentifikasi masalah dan menggali informasi melalui diskusi kelompok dan sumber belajar yang lain. Selanjutnya, siswa melakukan pembuktian dengan mempresentasikan hasil diskusi, kemudian siswa menarik kesimpulan. Pelaksanaan pembelajaran di kelas XI MIPA, siswa mempelajari materi dengan melakukan praktikum. Siswa melakukan praktikum pada materi hidrolisis dan larutan penyangga. Siswa melakukan praktikum dengan melihat petunjuk kerja yang sudah disiapkan oleh guru dan mulai melakukan identifikasi dalam kelompoknya. Setelah siswa melakukan praktikum, guru menjelaskan materi dan membahas praktikum yang dilakukan. Pertemuan selanjutnya, siswa hanya mengerjakan Unit Kegiatan Belajar Mandiri (UKBM) selama proses pembelajaran.

Model pembelajaran yang digunakan kelas X MIPA adalah discovery learning. Model pembelajaran yang digunakan pada perencanaan pertama menggunakan model pembelajaran inkuri terbimbing dan pada perencanaan kedua menggunakan model discovery learning. Pada perencanaan yang lain, guru hanya menggunakan model pembelajaran discovery learning. Secara garis besar prosedur dari model discovery learning adalah (1) stimulation/memberikan rangsangan, (2) problem statement, (3) data collection, (4) data processing, (5) verification/pembuktian, (6) 
generalitation/menarik kesimpulan (Gunarto, 2013). Model yang digunakan guru kimia kelas X MIPA pada perencanaan kedua sudah sesuai dengan langkah dari model pembelajaran tersebut. Model pembelajaran yang digunakan pada perencanaan pertama berbeda dengan langkah dari model pembelajaran tersebut. Hal tersebut karena guru memiliki keterbatasan waktu. Proses pembelajaran yang dilakukan guru di kelas XI MIPA berbeda dengan model pembelajaran yang direncanakan. Model pembelajaran yang dirancang guru adalah model pembelajaran problem based learning. Berdasarkan hasil studi dokumen, guru hanya menggunakan model pembelajaran problem based learning pada perencanaan yang lain. Langkah-langkah model pembelajaran problem based learning adalah (1) orientasi peserta didik pada masalah, (2) mengorganisasikan peserta didik, (3) membimbing penyelidikan individu dan kelompok, (4) mengembangkan dan menyajikan hasil, (5) menganalisa dan mengevaluasi proses penyelesaian masalah (Trianto, 2009). Pada pelaksanaannya, model pembelajaran yang digunakan guru kimia kelas XI MIPA belum sesuai dengan langkah dari model pembelajaran tersebut. Pada proses pembelajaran kimia kelas XII MIPA hanya pembahasan latihan soal.. Pembahasan latihan soal dilakukan untuk mempersiapkan siswa menghadapi Ujian Nasional Berbasis Komputer (UNBK). Oleh karena itu, model pembelajaran yang digunakan guru tidak terlihat pada saat proses pembelajaran.

\section{4) Sumber Belajar}

Sumber belajar yang digunakan dalam program full day school di SMA Negeri Bali Mandara yaitu UKBM, buku paket kimia, internet, video, dan e-learning. UKBM digunakan dalam pembelajaran saat siswa melakukan diskusi. Selain itu, UKBM juga dikerjakan oleh masing-masing siswa sebagai tugas. UKBM juga digunakan sebagai syarat untuk mengikuti ulangan harian. Sebelum mengikuti ulangan harian, siswa harus mengumpulkan UKBM sesuai materi ulangan harian yang akan diikuti siswa.

Buku paket kimia digunakan guru sebagai acuan dalam pemberian materi pelajaran untuk siswa. Buku paket kimia digunakan siswa untuk belajar dan membantu mencari informasi saat melakukan diskusi kelompok dalam mengerjakan UKBM. Internet digunakan guru untuk mencari video terkait materi yang diajarkan. Selain itu, Internet digunakan guru untuk mengakses $e$ learning. E-learning digunakan guru untuk menjelaskan materi pelajaran. Internet digunakan siswa untuk mencari informasi lain jika jawaban tidak ditemukan pada saat melakukan diskusi kelompok. Selain itu, internet digunakan siswa untuk mencari informasi yang tidak ada di sumber belajar yang digunakan di kelas. Video pembelajaran digunakan guru untuk membantu dalam penyampaian materi pelajaran, sehingga dapat menarik perhatian siswa. E-learning yang digunakan di antaranya zenius prestasi, quipper, dan psychology. E-learning yang digunakan terdapat materi pelajaran, latihan soal hingga pembahasan soal, dan video pembelajaran. E-learning ini digunakan siswa saat belajar mandiri atau pembelajaran tidak diisi oleh guru.

Sumber belajar yang digunakan sudah memenuhi tuntutan kurikulum 2013. Sumber belajar direkomendasikan oleh kurikulum 2013 buku teks pelajaran. Selain itu, sumber-sumber yang digunakan sebagai bahan belajar salah satunya adalah buku pelajaran (Hamalik, 2012). Namun, sumber belajar yang tercantum di perencanaan hanya buku paket kimia. Guru hanya mencantumkan buku paket kimia sebagai sumber belajar di perencanaan karena guru tidak bisa manuliskan semua sumber belajar di RPP. Sumber belajar yang siswa gunakan itu tidak terbatas. Siswa diperbolehkan menggunakan sumber belajar apa saja, mulai dari internet, e-learning, video dari youtube, ataupun sumber belajar yang lain.

\section{5) Distribusi Waktu Belajar}

Waktu belajar kimia dominan dilakukan pada pagi hari. Waktu belajar kimia di SMA Negeri Bali Mandara sudah sesuai dengan Permendikbud RI Nomor 22 Tahun 2016. Pada Permendikbud RI Nomor 22 Tahun 2016 tentang Standar Proses, alokasi waktu untuk satu jam pembelajaran untuk SMA/MA selama 45 menit. Pembelajaran kimia di kelas X MIPA terdapat satu kali pertemuan dalam satu minggu di setiap kelasnya. Satu kali pertemuan berlangsung selama 3 × 45 menit. Distribusi waktu belajar kimia kelas XI MIPA terdapat perbedaan. Perbedaan yang terjadi, yaitu dua kelas mendapat satu kali pertemuan dalam satu minggu dan satu kelas mendapat dua kali pertemuan dalam satu minggu. Kedua kelas yang mendapat satu kali pertemuan dalam satu minggu berlangsung selama $4 \times 45$ menit, sedangkan satu kelas yang mendapat dua kali pertemuan dalam satu minggu berlangsung selama $2 \times 45$ menit di dua hari yang berbeda. Mukminan (2013) menyatakan bahwa alokasi waktu belajar per minggu mata pelajaran kimia pada kelas X MIPA selama tiga jam pelajaran dan XI MIPA selama empat jam pelajaran. 
Distribusi waktu belajar kimia kelas XII MIPA digabung sesuai mata pelajaran yang dipilih untuk mengikuti Ujian Nasional Berbasis Komputer (UNBK). Waktu belajar kimia kelas XII MIPA mendapat 13 jam pelajaran dengan empat kali pertemuan dalam satu minggu. Waktu belajar kimia kelas XII MIPA ditambah dengan kelas Ujian Nasional Berbasis Komputer (UNBK) pada sore hari selama dua jam pelajaran. Total jam pembelajaran kimia yang didapat kelas XII MIPA selama 15 jam pelajaran dalam satu minggu dan untuk satu jam pelajaran selama 45 menit. Waktu belajar kimia kelas XII MIPA belum sesuai dengan kurikulum 2013. Waktu belajar kimia kelas XII MIPA melebihi jam pembelajaran sesuai tuntutan kurikulum 2013. Waktu belajar kimia kelas XII MIPA selama empat jam pelajaran (Permendikbud RI, 2016), namun total waktu belajar kimia di sekolah berlangsung selama 15 jam pelajaran.

\section{SIMPULAN DAN SARAN}

Berdasarkan hasil dan pembahasan penelitian di atas, dapat disimpulkan bahwa Implementasi pembelajaran kimia dalam program full day school belum berjalan sesuai kurikulum 2013. Secara rinci, simpulan penelitian ini diuraikan sebagai berikut. (1) Pendekatan yang digunakan guru kimia dalam program full day school di SMA Negeri Bali Mandara adalah pendekatan saintifik. (2) Metode pembelajaran yang digunakan guru kimia dalam program full day school di SMA Negeri Bali Mandara yaitu tanya jawab, diskusi, penugasan, praktikum, dan presentasi, namun metode yang dicantumkan pada RPP tidak sama dengan metode yang dilakukan guru dan siswa mengerjakan UKBM sebagai tugas untuk dikerjakan di rumah. (3) Model pembelajaran yang digunakan guru kimia dalam program full day school, yaitu inkuiri terbimbing, discovery learning, dan problem based learning. Model pembelajaran kelas X MIPA menggunakan model pembelajaran inkuiri terbimbing (guided inquiry) pada perencenaan pertama dan discovery learning pada perencanaan kedua. Pelaksanaan pembelajaran pada perencanaan pertama belum sesuai dengan model pembelajaran yang direncanakan, sedangkan pelaksanaan pembelajaran pada perencanaan kedua sudah sesuai dengan model pembelajaran yang direncanakan. Model pembelajaran kelas XI MIPA adalah problem based learning, namun dalam pelaksanaannya berbeda dengan langkah model pembelajaran yang digunakan. Pada proses pembelajaran kimia kelas XII MIPA hanya pembahasan latihan soal, sehingga model pembelajaran yang digunkan guru tidak terlihat pada saat proses pembelajaran. (4) Sumber belajar yang digunakan pada proses pembelajaran kimia dalam program full day school di SMA Negeri Bali Mandara yaitu Unit Kegiatan Belajar Mandiri (UKBM), buku paket kimia, internet, video, dan e-learning. (5) Distrubusi waktu belajar kimia dominan dilakukan pada pagi hari. Waktu belajar kimia kelas X MIPA selama $3 \times 45$ menit dalam satu minggu. Waktu belajar kimia kelas XI MIPA kedua kelas yang mendapat satu kali pertemuan dalam satu minggu berlangsung selama $4 \times 45$ menit, sedangkan satu kelas yang mendapat dua kali pertemuan dalam satu minggu berlangsung selama $2 \times 45$ menit di dua hari yang berbeda. Waktu belajar kimia kelas XII MIPA berlangsung selama 15 jam pelajaran perminggu dan untuk satu jam pelajaran selama 45 menit.

Berdasarkan hasil temuan, pembahasan, dan simpulan, adapun saran disampaikan sebagai berikut. 1) Guru hendaknya merencanakan hal lain jika tidak melakukan praktikum, seperti memberikan media animasi mengenai praktikum tersebut. 2) Guru hendaknya melaksanakan pembelajaran dengan berpedoman pada RPP agar pelaksanaan pembelajaran lebih terstruktur dan terarah. 3) Kebijakan sekolah hendaknya tetap memerhatikan distribusi waktu belajar kimia agar tidak melebihi waktu belajar siswa yang sudah ditentukan dalam kurikulum 2013.

\section{DAFTAR RUJUKAN}

Baharudin. 2009. Pendidikan \& Psikologi Perkembangan. Jogjakarta: Ar-ruzz Media

Gunarto. 2013. Model dan Metode Pembelajaran di Sekolah. Semarang: Unisulla Press.

Hamalik, O. 2012. Kurikulum dalam Pembelajaran. Jakarta: PT Bumi Aksara.

Hidayah, Nur. 2017. Kesiapan Sekolah dalam Implementasi Program Full Day School (FDS) SD Muhammadiyah di Kota Yogyakarta. Jurnal JPSD Universitas Ahmad Dahlan Yogyakarta, Volume 4, Nomor 1.

Leasa, Marleny dan Batlolona, John. 2017. Full Day Scool dalam Pembentukan Karakter Siswa SMK N 13 Kota Malang. Jurnal Pendidikan Universitas Pattimura Ambon, Volulme 6, Nomor 1.8 
Mukminan. 2013. Kurikulum pada Jenjang Pendidikan Dasar dan Menengah. Makalah. LPMP Universitas Negeri Yogyakarta.

Syah, Muhibbin. 2004. Psikologi Pendidikan dan Pendekatan Terpadu. Bandung: Remaja Rosdakarya.

Naway, F.A. 2016. Strategi Pengelolaan Pembelajaran. Gorontalo: Ideas Publishing.

Nurdyansyah dan Fahyuni, E. 2016. Inovasi Model Pembelajaran. Sidoarjo: Nizamia Learning Center.

Peraturan Menteri Pendidikan dan Kebudayaan Nomor 22 Tahun 2016 Tentang Standar Proses Pendidikan Dasar dan Menengah. 2016a. Jakarta.

Peraturan Menteri Pendidikan dan Kebudayaan Republik Indonesia Nomor 23 Tahun 2016 Tentang Standar Penilaian Pendidikan. Jakarta: Mendikbud RI.

Permendikbud. 2017. Permendikbud Republik Indonesia Nomor 23 tahun 2017 tentang hari sekolah. Jakarta: Mendikbud.

Rizky, A. A. 2015. "Problematika Pembelajaran System Full Day School Siswa Kelas 1 SDIT ALIrsyad Tegal." Skripsi (tidak diterbitkan). Fakultas IImu Tarbiyah dan Keguruan. Universitas Islam Negeri Walisongo. Semarang.

Setiawan, dkk. 2018. Profil Pembelajaran Kimia Berbasis Kurikulum 2013 di Kota Gorontalo dan Kota Surakarta Kelas X Tahun Ajaran 2016/2017. Jurnal Inovasil Pendidikan Kimia Universitas Sebelas Maret. Volume 12, Nomor 1 (hlm 2039-2054).

Setianingtyas, Yosi Dita. 2015. "Implementasi Program Full Day School di Sekolah Dasar Islam Terpadu (SDIT) Bakti Insani Sleman Yogyakarta." Skripsi (tidak diterbitkan). Universitas Negeri Yogyakarta.

Sugiyono. 2012. Metode Penelitian Kuantitatif, Kualitatif, dan R \& D. Bandung: Alfabeta.

Sulaeman. 2015. Pengembangan Kurikulum 2013 dalam Paradigma Pembelajaran Kontemporer. Jurnal Pengembangan Kurikulum Universitas Muhammadiyah Purwekerto, Volume 14, Nomor 1.

Trianto. 2009. Mendesain Model Pembelajaran Inovatif-Progresif: Konsep, Landasan dan Implementasi pada Kurikulum Tingkat Satuan Pendidikan (KTSP). Edisi Pertama. Cetakan Ke-1. Jakarta: Kencana Prenada Group.

Undang-Undang Republik Indonesia Nomor 20 Tahun 2003 Tentang Sistem Pendidikan Nasional. 2003. Jakarta.

Wiratma, I G.L. 2013. "Pengelolaan Pembelajaran Kimia pada SMAN 1 Singaraja dan SMAN 1 Gianyar: Dekontruksi Implementasi Standar Proses". Disertasi (diterbitkan). Program Studi Kajian Budaya, Program Pascasarjana Universitas Udayana. 